\title{
1 The computer game as fictional form
}

For when the One Great Scorer comes

To write against your name,

He marks - not that you won or lost -

But how you played the game.

(Grantland Rice)

Life's too short to play chess. (H. J. Byron)

The origins of this project can be located in an experience that could not have been further distanced, at the time, from the academic practice and teaching of cultural and literary criticism which usually fills my days: the successful conclusion of Close Combat II: A Bridge Too Far (1997), a strategic wargame set in the Second World War. In addition to the usual feelings of unease at the amount of potentially productive research time that I had spent in solitary 'communication' with the intriguingly named, and necessarily limited, 'artificial intelligence' that was produced at the intersection between the game's designers and my even then lowly Pentium $166 \mathrm{MHz}$ processor, I had a growing feeling of disquiet at what I had been engaged in as the final clip of film rolled. Black and white archive footage of a ceremony at which bearded and exhausted Wehrmacht soldiers received decorations in the field was accompanied with a stentorian voice-over delivered in a thick Hollywood-German accent. Apparently, my leadership qualities had earned me the personal thanks of Berlin. In destroying the bridgehead at Arnhem, and stalling the Allied armoured advance well before it reached Nijmegen, I had been responsible, potentially, for altering the course of the war in the West. Bully for me. 
The intrusion of language into the world of the game had pulled me up short. Intellectually capable as I was of divorcing the abstract gameplay and pixelated graphics that had eaten into my spare time over a number of weeks from any notion of a 'real' Second World War, a 'real' parachute assault on Arnhem, and a 'real' Adolf Hitler, winning not just the game, but the approval of even a simulation of Nazi Germany left me feeling a little flat, to say the least. I was also well aware that if I mentioned my military triumph in the English department where I am a lecturer, then I might find myself treated with the kind of suspicion usually reserved for those who appear to have mistaken the military history section of the bookshop for the top shelf of a newsagents as they browse hard-back illustrated volumes with titles like Uniforms of the Waffen-SS, 1939-45, or Camouflage Schemes of Operation Desert Storm. Playing games with virtual toy soldiers and rewriting the history of the Second World War to the advantage of Nazi Germany was nothing to be proud of.

And yet there was something here that was as intriguing as it was disturbing. A game that was marketed through a rhetoric of 'authenticity', as 'realistic' and a 'simulation', had led to a substantially inauthentic deviation from its ostensible historical referent. In layman's terms, somewhere in the interaction between myself and the game a fictional version of a historical military campaign had been created. That I had largely been led by the nose through a series of extremely restricted episodes representing small-scale military conflicts in order to construct this narrative did not interest me so much as the process of construction itself. Perhaps there were the first signs here of a form of fiction that I had not been aware of before, the creation of a new type of 'text' that required critical reading in a way that differed from the critical reading of novels, films or television texts? As an increasingly popular form of fiction that made grand claims for authenticity and realism in its marketing, and presented a type of what I thought I recognised as storytelling outside language, the computer game certainly seemed to demand further consideration. 
At the risk of indulging in the sort of pretentiousness that sees academics making an occasional unwelcome appearance in Private Eye magazine's 'Pseuds Corner', it also seemed that I had encountered something that might have at least tenuous connections with what has come to be termed 'counterfactual' history and has seen popular expression in novels such as Philip K. Dick's The Man in the High Castle (1965) or, more recently, Robert Harris's Fatherland (1993). I had, in my own limited and solitary way, been as much engaged in the exploration of the historical 'what if?' as any of the contributors to Niall Ferguson's edited collection of essays, Virtual History: Alternatives and Counterfactuals (1998). There was a tension inherent in this form of game between historical truth claim and fictional possibility. Its counterfactual potential might have been severely limited (the Allied defeat at 'the bridge too far' at Arnhem is a historically verifiable event, as well as a successful film) but it was nevertheless present (the extent of that defeat was nothing like the game experience). The extent of the deviation from the report of historical event, apparently, had been my responsibility. Fiction and history appeared to be caught in a complex relationship that needed teasing out.

Computer wargames such as the Close Combat series display a near-obsession with questions of historical authenticity and realism. In terms of the details of weapons performance, unit deployment, and terrain modelled on period aerial reconnaissance photographs, Close Combat seeks to attain a level of detail that would satisfy the most retentive of military history's trainspotters. In a phrase discussed further in Chapter 4, the manual for one game in the series declares that it 'puts the emphasis on real' within the genre of 'real-time strategy' games. Yet it was something that had emerged out of a lack of correspondence with real event that is inherent in this kind of game that had most disturbed me (the variant narrative that I had constructed, or at least been complicit in constructing), and notions of fiction-making that had most interested me. 
The initial feelings of disquiet remained, however. The very abstraction of the game's structure, and its status as (just a) game, provided a defence against some of the most obvious forms of criticism that such a fiction might encounter. This was the kind of 'clean' representation of warfare of which Brussels and Washington can only dream. No Dutch citizens are caught in crossfire or risk reprisals - this German war-machine is the product of programming information and not of an economy dependent on slave labour. The politics of the story are just not an issue. The armchair general faced with a computer did not have to concern himself or herself with questions of right or wrong, or separate the good guys from the bad guys. It all depended, quite literally, on your 'point of view'. In this text the human tragedy and drama of the Second World War, and even the human evil of Nazi militarism, had no relevance - all that was offered were a series of equations and apparent facts free from the implied moral judgements of storytelling as I moved the mouse and tapped the keyboard.

I was reminded of Ernest Hemingway's famous and oftquoted statement on the consequences of the experience of modern warfare in A Farewell to Arms (1929):

[there] were many words that you could not stand to hear and finally only the names of places had dignity. Certain numbers were the same way and certain dates and these with the names of places were all you could say and have them mean anything. Abstract words such as glory, honor, courage, or hallow were obscene beside the concrete names of villages, the numbers of roads, the names of rivers, the numbers of regiments and the dates. ${ }^{1}$

What Close Combat seemed to provide was a version of postHemingway recounting of war, albeit one with which even such a believer in the beneficial nature of sports and games with clearly defined rules might well have had little sympathy. Hemingway's narrator is seeking escape from the betrayal of a particular kind of narrative, that of propaganda: the player of Close Combat was freed 
from received historical recounting. Until that final voice-over, he or she was released, even, from the kind of judgements inherent in the construction of story through language. An elimination of connective narrative accounting (the links between isolated 'facts' that give story its meaning) left only those isolated and apparently objective fragments of data which, like the sidebars of historical information to be found within the printed manuals for Close Combat, provided a fractured version of the past uncluttered by political, economic, social and (most particularly) human context. On the level of the individual story episode the player was provided with the building blocks of a story that was then 'written' or 'told' through its playing out according to the internal logic of the game. Here was a form of fictional freedom: I could tell the story again and again and bring the story to a variety of conclusions. Here was a form of fictional restraint: I could only tell the story in a particular way. There really was something here that demanded further thought.

That the computer game has not, to date, received much serious critical attention as an independent form of fictional expression, rather than in passing as a technological curiosity or as a springboard for some extremely speculative theorising about the possibilities that might one day be revealed in virtual reality or cyberspace is hardly surprising, however. If this is a form of fiction, then it is still perceived as a form of fiction for children and adolescents, with all the pejorative associations that such a classification carries with it. Games, with their vast time demands and lack of discernible product in their near-onanistic engagement of an individual with a machine, have hardly been welcomed with open arms by the parents of their target audience. 'Adult', when it is invoked as a term at all, most often equates with 'pornographic', rather than 'sophisticated'.

That some of the same criticisms made of computer games might be levelled at the practice of reading more traditional texts (no clear product, time taken up that might be better used running 
around in the open air, the generation of what appears to be obsession in genre fictions like J. R. R. Tolkien's The Lord of the Rings (1954-55)) does not seem to have broken down the basic antipathy towards the game element of the computer game. Reading has 'value', even the reading of the most popular forms of genre fiction: the playing of games 'wastes time' that might have been put to better use.

If one were to push a comparison between the computer game and literature further, then the concentration of game designers and consumers on genres that are fairly low down the literary pecking order (war, science fiction, fantasy) does little to add to the respectability of the computer game. But it might be as shortsighted to ignore questions of how we 'read' computer texts, and how they communicate their meanings, particularly in this time of increasing computer 'edutainment', online education, electronic publishing, and increasing Internet use, as it would be to ignore questions of just how we read other forms of popular text.

Looking along the CD rack beside my computer led me to a series of further digressions that would eventually take in the serious consideration of games belonging to a range of what appear at first to be very different sub-genres. Games as superficially diverse as 'first-person shooters', 'third-person adventures' and those management games often referred to as 'god games' appeared to be creating fiction in new ways just as much as the real-time strategy game Close Combat. What connected many of the games I had played, however, was the way in which they claimed varieties of 'realism'. If the computer game is another form of fiction, as I have come to believe and argue throughout this volume, then it is different in more than mere technicalities of form from film, television, or prose fiction. The stories we read in computer games are not just pale reflections of novels, plays, films, or television programmes, but they have a different relationship with both other textual forms and the 'real world' that it (and other forms of 'realist' fiction) claim to represent. As telling a story on the written page 
has different demands, constraints and freedoms, as well as conventions of representation, than the telling of a story on the stage, or on film, or on television, so the telling of stories within computer games works with different conventions that are not solely located in its foundation on the basic binary operation of the computer's processor. The technology deployed in the service of the computer game is important, and requires due attention, but it is at least as important to pay close attention to the ways in which games designers and players have exploited the strengths and weaknesses of the modern computer as a vehicle for the delivery of fictional texts.

The computer game's claims to authenticity and realism, whether in terms of historical simulation and the accuracy of its data arrays, the 'real physics engines' of flight and road simulations, the advances in graphics that now see mirrored reflections off surface water and deep shadows cast by flickering light sources, or the complex algorithms that lie underneath the often jolly graphics of management games such as the Civilization or SimCity series, all seem to demand a particular kind of investigation. The fundamental differences between these various forms of computer game also need identification if we are to comprehend their varying intersections and engagements with the terms 'realistic' and 'simulation' that so often appear on their packaging.

The invitation to a particular individual and even unique form of 'reading' that such games offer within a reader-text interaction that is qualitatively removed from that offered by other visual or written forms similarly requires examination. If we accept that we are confronted with a form of narrative storytelling where the production of story is the end result of play, as well as with a game where 'winning' is everything, then analysis of those storytelling processes becomes necessary. As a primarily literary critic, with some background in academic historiography (the study of how history is written), this new mode of computer-based storytelling seems to me to be both amenable to contemporary 
literary-critical practice, and related practices deployed within cultural studies, and to demand a somewhat different critical approach. The formal characteristics of this as an independent form need examination if the computer game is to be treated with the seriousness, as a massively popular form of cultural expression, that it deserves. To simply condemn or ignore this developing form of fiction as 'childish', rather than recognise its 'immaturity', might well be a mistake. This study offers suggestions, through example, of a practice of reading computer games that in no way constitutes a rigid methodology, but might be among the first faltering steps towards such a critical undertaking. I make no apology for the concentration on questions of narrative practice that may appear to be fairly old news for those who are familiar with contemporary critical theory as it has been read in relation to literature and film. Such areas as I attempt to cover in detail, including narrative 'point of view', the possibility of 'subversive readings', 'closure', the meaning of terms such as 'realism', 'counterfactual historiography' and the handling of time within narrative are in no way original to me the originality of the intervention I intend to make is in my consideration of these terms and ideas when we look at specific works in detail, rather than fall into the trap of writing in vague and general terms about the computer game in the abstract.

\section{The postmodern temptation}

Plenty of writers of more or less unreadable critical and theoretical works have claimed that their books are intended for that mythical beast 'the general reader', and I am not keen to join their company. I have, therefore, attempted to keep the amount of theoretical jargon (rather than serious thought) to a minimum. Nor am I alone in my scepticism towards some of the more extreme language that can be used when this new technology is up for discussion. As Jon Covey has argued in his introduction to Fractal Dreams, 'Each onslaught of hyperactive technobabble becomes more tedious than the last, until we become just plain bored. ${ }^{2}$ I would not even attempt 
to glorify my own argument - it is intended to be introductory, preliminary, and to raise questions as to where we go next as critics and readers, as much as it is intended to provide comprehensive answers about the past, present, or future of the computer game. The endnotes are there for those who want them, although not to any length or extent that would protect this work from possible charges of being overly reductive in aiming for clarity of argument over fullness of scholarly reference. The computer game-fiction is a form of popular fiction and I, like many other critics who work in the hinterland of what goes under the name of cultural studies, would argue that scholarly rigour is as essential in approaching such popular texts (and I use Roland Barthes' term 'text' selfconsciously, just as I have insisted on the italicisation of their titles as if they have equal standing with films or novels) as it is when approaching the supposedly high-cultural textual artefact. This present work, however, is primarily intended as introductory in tone and content - I do not want to bury my arguments for what is new, distinct, or different in this form of popular entertainment too far under a language or methodology that is undeniably popular in academia, but is rarely accessible, understood, or even particularly popular beyond its confines. I seek to inform, but not to validate my arguments through either jargonistic 'technobabble' or philosophical musings that are not firmly anchored in observation.

That said, I freely admit that I have drawn far more on theories of narratological analysis (and to give an early example of the kind of simplifying gloss I will be guilty of throughout this study, I would define narratology for my purposes here as the study of how stories are told) than on poststructuralist or even postmodern thought. ${ }^{3}$ My ambition is relatively limited - the games I isolate as my examples, I contend, require informed reading as fiction and as texts. They deserve, and get in this study, no more and no less. To give an early indication of where I hope to have travelled to by the end of this study, my provisional answer to the 
question of whether the computer game is 'more than a game' is a qualified 'yes' - it can also be a form of fiction making, and in the cases I isolate presents a fictional text that rewards close critical scrutiny. Is it 'more than a game' in that it requires a reformulation of our understanding of self, identity, art, or culture? Is it representative of a truly radical break with the ways in which we have previously told ourselves our stories? 'No', or at least 'No, not yet.'

This is a form of self-denial and self-restraint, and not always of ignorance. This is not intended to be a work of theoretical enquiry, but a work of close textual criticism. In concentrating on specific game-fictions as fictions, and looking in detail at concrete examples of the form, I try to avoid making too many hyperbolic claims, and to restrict myself to that which can be supported by readings sourced in the texts themselves. Specifically, I have recognised in myself a tendency to make too much of an apparent correspondence between the texts I have been reading 'through' or 'on' my PC and PlayStation, and those I have been reading that exist within works of contemporary critical theory. What I have termed the 'postmodern temptation' in this section heading is something I have sought to both recognise and deny, partly to keep this study manageable, and partly to try and avoid moving too far into abstraction and generalisation. In particular, I have tried to avoid 'applying' theory to texts, and using the tricks and tropes of rhetorical argument to patch over the resulting gaps and absences.

Before I completely alienate a possible academic readership, however, I would like to make it clear that this is not an antitheoretical move. What I want to suggest is that it is far too tempting for the academic critic to consider the future possibility of what the computer game might become, rather than address the mundanity of the object we actually have access to. This is not that potentially oxymoronic thing, an 'untheorised reading'. Rather, it is a reading that draws on narratological and structuralist thinking and criticism for the most part, and tries to leave its more speculative digressions until the closing chapter. Those who wish to read 
about Tomb Raider, Half-Life, Close Combat, or SimCity are advised to skip ahead to the beginning of Chapter 2 and read on. Those who wish to see if I have anything new to say about the future possibility of the computer game might be best advised to endure this section of the text and then skip ahead to Chapter 6. Much of the (hopefully unobtrusive) theoretical material that follows and informs this study emerged out of enquiries into supposedly 'simple' or 'primitive' narrative forms such as the fairy tale or folk tale, and seems to have particular utility in the examination of the computer game if we recognise its own 'primitive' or 'simple' current state. What theoretical material there is that talks to and about intimately related cultural phenomena such as 'virtual reality', however, is concerned with a far more complex and sophisticated object of study. Jean Baudrillard's essay 'Aesthetic Illusion and Virtual Reality', discussed in Chapter 6, for example, would seem to be as astute and as forcefully argued as much of his other work, but not to be straightforwardly applicable to the world of 'left click this', 'hit that shortcut key' and 'save the game'.

The very materiality of the experience of playing the computer game, its engagement with bits of plastic and metal, silicon and glass, fix it still within the age of mechanical reproduction that was identified by Walter Benjamin even as there is a potentially digital or even 'cyber' age evolving or revolving about it. ${ }^{5}$ Things might be about to change, but the reality of playing computer games at the turn of the twenty-first century requires a mass of cables and plugs and extensions. Wires snake about everywhere. Get too involved in playing and your back will ache, your eyes will suffer strain and your mouse hand will begin to cramp. The computer game takes its toll on the body even as it promises a disembodied and virtual experience. Next time we feel inclined to chuckle about our digital forebears and find it amusing that huge mechanical monsters used to occupy the computer departments of our universities, we should take a long hard look at the cables and peripherals that trail across the floor of our living rooms or underneath 
our desks and computer stands. The machine remains a physical presence, and a bulky one at that. And if we should ever feel the urge to stress just how primitive it was to shove stacks of cards punched with holes into early computers then we might reflect on what we are doing as we drop another disk into the CD drive of our PC or console. Our more elegant contemporary machines, our iMacs and laptops, might not be the physical mess of your average PC setup at the turn of the twenty-first century, but they remain bulky reminders of the physical (and not virtual) nature of the phenomenon.

The language that surrounds the computer game (terms such as 'game' and 'play') and the language that surrounds other emergent forms of computer-dependent text (such as 'hypertext' and 'simulation'), offers an almost overwhelming temptation to its early critics, who appear - like me - to be faced with something that seems to emerge out of that particular period that Fredric Jameson has termed 'late capitalism', and Jean Baudrillard has characterised as 'the "proteinic" era of networks ... the narcissistic and protean era of connections, contact, contiguity, feedback and generalized interface that goes with the universe of communication', and to already share a basic terminological vocabulary with much postmodern thinking. ${ }^{6}$ As such it is tempting to point either an admonitory or celebratory finger at computer games and declare them to be somehow symptomatic or representative of the postmodern. Those who would see the postmodern as a moment (an extended cultural event, a period), rather than a practice or loose collection of practices, might be forgiven for making immediate connections between this moment and a cultural product that so firmly belongs to it. The formulation is simple, if not simplistic. Now is postmodern. The game-fiction did not exist before now. The game-fiction is therefore postmodern. QED. Or, to use the language of the early arcade video games, 'Game Over'.

Leaving aside any evaluation of the utility of making such a critical move for a moment - that does little more than slap a 
dated label on the side of the game-fiction and remind us that it is undeniably contemporary - it is nevertheless worth spending a little time tracing some of the more subtle connections that can be made, and that I have nevertheless avoided drawing on too heavily in the case of the individual textual studies examined here. We should always remember Jameson's own characterisation of the postmodern as a site of contestation rather than critical or definitive certainty, but several early interventions in the debates that have surrounded the postmodern are worth examining briefly here. ${ }^{7}$ The postmodern theorist Ihab Hassan's oppositional list of binary categories, for example, might have been received with understandable scepticism, and be open to criticism for its portrayal of a clearly defined modernism and a clearly defined postmodernism drawn up in battle lines rather than in intersection and debate, but it still offers some potential illumination as to why it is so tempting to see the computer game as being locatable within postmodern theoretical frameworks:

Modernism
purpose
design
centering
genre/boundary
interpretation/reading
lisable (readerly)
origin/cause

Postmodernism
play
chance
dispersal
text/inter-text
against interpretation/misreading
scriptable (writerly)
difference-différance/trace

Were we to accept such a pair of lists without the usual pinch of salt we might think that the computer game might be firmly placed in the postmodern camp, and might even be representative, to follow Hassan's more complex argument in The Dismemberment of Orpheus, of a postmodern fictional form of representation that can truly be termed 'anti-elitist' (essentially popular, democratic, even demotic), rather than 'elitist' (text always fixed within hierarchies of value and reference) in a fashion that has proved problematic within literary criticism. To begin with the obvious, and in 
recognition that the compound term game-fiction I deploy throughout this volume incorporates rather than rejects the game element within game-fiction, it is certainly a case of 'play' over 'purpose', as so much of the negative criticism levelled at the computer game has made clear. ${ }^{9}$ Less certainly there is the presentation of chance over design - as the game reproduces the effect of 'chance' (the availability of plural possibility) over 'design' (the inevitability of a singular outcome, some kind of fixed and 'authored' outcome). Similarly, we see in that plurality of possibility a 'dispersal' rather than a 'centering,' and at least the illusion of the scriptable (writable, privileging the reader) over the lisable (readable, privileging the author). ${ }^{10}$ What we would lose if we succumb too readily to such critical temptations, however, would be this need for a specificity of analysis. As enough literary critics have found, if we are not careful in our definitions we are in danger of finding 'the postmodern' in every time and place, in the history plays of Shakespeare, and in the very first novels in English. I sometimes wonder what we might make of the prehistoric cave art of Lascaux if we always carry our postmodern critical apparatus with us when we confront an artwork.

Having been subject to intense theoretical debate since the 1970s, terms such as 'simulation' and 'hypertext' also press obvious critical buttons. In the terms of common usage (at least with regard to the textual organisation of the World Wide Web, both within specific pages and between websites), 'hypertext' offers nonlinear and non-hierarchical communicating linkages between textual fragments, but it is not simply a technological enactment of what Gérard Genette is concerned with when he discusses 'hypertextuality'. ${ }^{11}$ Context might well be boundless, but we would do well to remember its specificity. As Jean Baudrillard has noted when discussing 'simulation' in a wider social and cultural context it is possible to argue that 'simulation threatens the difference between 'true' and 'false,' between 'real' and 'imaginary.' ${ }^{12}$ As such it seems to offer an attractive point of access for thinking through 
the computer game - particularly for those who might foresee a technological future in which we might 'lose ourselves' in the 'consensual hallucination' of the 'matrix' of cyberspace. ${ }^{13}$ We should, however, continue to be careful in our use and understanding of such terms, never coined and rarely subject to critical reassessment in the face of the encounter with the computer game. As the actual experience of reading computer games should remind us, such terminology does not always survive its transportation to the specifics of that experience. I would ask the reader to pause and insert the words 'computer game' before Baudrillard's statement. Is 'true' and 'false', 'real' and 'imaginary' really 'under threat' in such games?

It is worth pointing out here that the 'sim' of SimCity is truncated and partial for a reason - 'simulation' in computer games is not the same as the kinds of 'simulation' that necessarily pose any such 'threat'. In the games themselves, rather than the hyperbolic copy written by their promotional teams, they rarely support any claim to threaten this distinction in any meaningful way. In Chapter $3 \mathrm{I}$ argue in detail that if the first-person computer game is simulating something, then it is certainly not simulating lived experience. It might, however, be useful in explaining my reticence towards 'using' postmodern thought if we quickly look here at some of the ways in which we can draw a distinction between Baudrillardian 'simulation' and the forms of 'simulation' one actually encounters within the computer game as it currently stands. In Gunman Chronicles (2000), for example, we encounter a comparatively advanced visual experience that uses the same graphics engine as Half-Life. It is presented from a first-person point of view that allows us to pretend that we are 'in' this environment. Gunman Chronicles is a three-dimensional text, in which we use a combination of mouse and keyboard to move about this 'virtual' world. Largely we move about in order to reposition the gunsight that allows us the crude form of interaction (shooting things) that is central to the playing of the game, but we are also provided with an illusion of freedom of visual movement. Playing for a while, how- 
ever, indicates that there is a hierarchy of effective 'simulation' in the game. The artificiality of topography and architecture are barely noticeable as we become accustomed to what amounts to the visual 'style' of the game. There are too many angles and bright colours for this to be convincing in its illusory potential, but not in a way that intrudes too much on our reading experience. Water does not look like 'real' water, but is recognisable as water in terms of negative definition. It has enough markers of the characteristics of water (it moves, it reflects, it is semi-transparent) that we recognise it as not earth, not corridor, or not lava.

But the human figures of the other gunmen that move and shoot and run about this landscape are recognisably not human. We might be fooled for a moment that they looked 'as if' they were human, that there was ever an 'original' (as there is in the traditional filmed image before it is manipulated in the studios of Industrial Light and Magic), but not for long. Glimpsed for an instant in the distance we might not bring our knowledge of their graphic limitations to mind. But close up, they look remarkably inhuman - there is little individuation, they 'pose' like bodybuilders at rest rather than stand naturally, and they are square-jawed not because they are action heroes, but because the framework of graphical boxes (or polygons) from which the image is composed is still evident on the most superficial level. The games designers have built in some nice touches, and these figures twitch and fidget with small random movements rather than stand stock-still, for example, but there is absolutely no way that anyone could mistake the computer-generated image for an apparent image of the real such as film. When the figures speak then the lack of effective lipsynching reminds us of just how primitive this is if it is understood to be an attempt at 'simulation'.

Computer-animated films that have attempted this feat of presenting an image with no original as if there was an original, such as Shrek (2001), Monsters Inc (2002) or Final Fantasy (2001) are interesting enough as technical demonstrations of what hap- 
pens visually when millions of hairs are modelled individually, or how the potential of each successive advance in computer processing power is harnessed to give apparent texture to skin, but in their attempt at the representation of the human always suffer comparative failure. Who could not have noticed, for example, that Princess Fiona in Shrek is far more 'convincing' a figure when she is in ogre form than when she is her 'human' self? Or that the toys of Toy Story 'convince' in a way that the humans do not? Ogres, or the walking eyeball of Monsters Inc, or the hardware of a science fiction future in Final Fantasy, are comparatively convincing in their 'illusion' that the image presented could have been connected mechanically with a 'real' object because that 'real' object is actually located within the imagination (and our tradition of representation of the imagination) and not in the observed world. This is far harder to achieve digitally when it is poor flawed humanity that is the subject of representation. And I am sure those actors who provide the voices so essential to the success of such films will be laughing all the way to the bank when they read of the imminent redundancy of the human because of technological advance.

It is telling that where a game like Gunman Chronicles succeeds visually is in its rendering of images that have no meaningfully real reference - at the top of its hierarchy of 'simulation' is not the human or the inanimate, but the dinosaurs that populate the first alien landscape that the player encounters. Of course, when we test the representation of the human in the computer game for its 'accuracy' or its 'realism' we make comparison with the observed real as well as with other acts of representation - when we test the 'accuracy' or 'realism' of the dinosaurs we test against a tradition of representation. These are not lizards with bits glued on, as we once encountered in the monster movies. Nor is this the stop-motion animation of models, as in films where animators such as Ray Harryhausen stunned audiences with the realism of the reptiles, such as One Million Years B.C. (1966). What it refers to is the current 'state of the art' and not the state of the real. Jurassic Park (1993) 
showed the way, and (at least in the UK) BBC television's Walking With Dinosaurs (1999) moved us a little further along. But at the end of this particular pathway is the 'imaginary' and not the observed 'real'. The sophistication, effectiveness, or plausibility of the dinosaurs on screen is judged within its comparison with the subsub-genre of the computer-animated dinosaur film, whether it claims to be documentary or entertaining in effect. For all any of us know (and I stress the 'know') all dinosaurs hopped and bounced about the landscape like squealing schoolchildren at playtime. Or had perpetual hiccups. Or had polka dot markings. I 'know' how they should move and look on screen, but I do not 'know' how they did move and should look in life. We might 'suppose' or even 'deduce' things from the fossil record, but we do not 'know' if and how simulation matches real. No human observed the creatures in question, and the prehistoric is best known for its lack of record keeping even when there was a human presence. It is a disappointment encountered by every schoolboy that no recognisable ancestor feasted on brontosaur steaks or ran from a marauding Tyrannosaurus rex. Use of flocking algorithms based on the observation of the flight of birds to model the behaviour of dinosaurs can only simulate the flocking of birds - otherwise we are left with the possible and the 'imaginary', whatever the stridency of the claims for the 'real' made by those who will take observation of one event to another. This takes nothing away from the images with which we are confronted, however. They are aesthetically pleasing, they offer the pleasure of spectacle, and there is something simply 'fun' about walking around the grazing dinosaurs or staring up at the wheeling pterodactyls in Gunman Chronicles before everything goes haywire and the running and shooting begins in earnest.

This is not to deny that the technology, rather than the deployment of technology within the computer game, cannot be read as posing a 'threat' to a distinction that is already under strain. The same technology that is used by the computer game obviously has the potential to deceive, and probably not too far in the future, 
if it has not done so already. But there again, so has the technology of the printed word, the technology of film, and the technology of television. I do not deny this potential, but would ask that we not leap too quickly to an assumption that the possibility for deceit demands more than the critical reading of such texts. We should learn to recognise what is self-evident 'fact' and what is self-evident 'fiction'. If we do not, we invite deception. But this is more an argument for considered and informed reading, and not blanket condemnation or even 'fear' of the computer game. We do not reject or condemn the fictional products communicated through the printed word because of the possibility of the criminal forgery, ignore the filmic text because its potential for deceit has been abused by some terrifying regimes, or stop ourselves from watching junk TV because it has consistently confirmed the $X$-Files maxim that 'the truth is out there' rather than within its own programming.

The basic point I make again and again by implication in this volume is that it is not always necessary, or even advisable, to turn immediately to the work of critics such as Baudrillard, Jameson, Hassan, or Umberto Eco (whose own discussion of 'hyperreality' similarly offers tempting connections) when confronted with the formal novelty of the computer game. ${ }^{14}$ In a sense, we should not get too excited (yet), we should not rush to declare that we occupy a new age of representation (yet). There is something new here, and something new in its emergence from the technological moment at which we are now placed, but it is not a new phenomenon that is ahistorical in its form or its reference. The game-fiction has not sprung fully formed from the depths of the machine, and the search for a radical break from previous modes of representation is likely to be futile, as is any assumption that it is only the cutting edge of contemporary critical theory that can inform our consideration of such a contemporary form. Rather, the need is (perhaps paradoxically) for us to locate the computer game in relation to other forms of fiction - to suppress this temptation to make corre- 
spondences of language stand in for actual correspondence, and to look in the first instance not for the philosophical questions the computer game might raise at some time in the future, but closely at the things themselves.

What is surprising, perhaps, is the degree to which it is possible to approach such texts in a critically sophisticated fashion without merely being left with a category statement. If we engage in the careful business of close textual analysis rather than leap immediately into the realms of speculative theory we might not just apply a convenient label, but recognise its formal novelty. In offering up the admittedly ugly coinage 'game-fiction' to describe the texts under scrutiny, I hope to communicate the narrowness of my enquiry and not just make my own error of reductive taxonomy. This is a work concerned with those computer games that I see as having a central narrative impetus, that develop story over time, rather than simply repeat with minimal difference in a move from level to level of increasing excess. Such a neologism signals a rejection of the alternatives as much as anything particularly startling about my specific examples. 'Videogame' overstresses sight with no reference to cognitive understanding, and the term I have used up until this point, 'computer game', speaks of the technology rather than the text. I am also aware that it is the personal computer, rather than the arcade cabinet, the games console linked to a television set, or the hand-held console with its minimal memory and tiny screen that I am interested in here. In part this is because I am interested in the multiplicity of utility (that consoles are moving to emulate) of the personal computer that sits on desks at home and at work, and particularly the ways in which this workhorse of labour in the early twenty-first century is where we read computer-based texts both for work and for fun. It is possible that one form of literacy (how we read the computer-based texts of the Internet, for example), might come to cross-pollinate with this other form of literacy in which I am interested - how we read game-fictions. 


\section{Reading game-fictions}

The concentration in this study on notions of authenticity and realism, beyond keeping it to a manageable size, should allow me to address another prevalent temptation. The sometimes understandable confusion that appears to exist in the popular mind, and particularly the popular press, regarding the effect of such simulations in the real world, and the supposed blurring of distinctions between game-worlds and the real world generate all sorts of negative comment. Too many things become confused, too many correspondences are made and generalisations allowed to stand without sufficient scrutiny. The remotely piloted vehicle used for space or deep-sea exploration, or for entry into hazardous environments such as the inside of nuclear reactors, is now a reality. It will not be long before such machines are deployed by the US military for first-strike missions. For all I know, they exist already. The interface between controller and real environment in such circumstances is often similar to that between player and game environment. As the use of video footage as part of the public relations offensive during Operation Desert Storm indicated, these all too real computerised interventions in the real world share many of the characteristics of their gaming cousins. Anecdotal and press accounts of more general confusion can range from the worrying (such as a USAAF mechanic who is rumoured to have learnt to fly a state of the art warplane using a flight simulator on his PC and then taken a real plane for a joyride), to the alarming (and possibly alarmist) tales of teenagers preparing for mass shootings using custom-designed levels for first-person shooting games that replicate the geography of their school buildings.

The relationship between fictional representation and real world acts of violence, whether supposedly inspired by films, novels, or computer games, is a notoriously thorny issue, but this formal examination of the computer game as fictional form is intended to clarify some of the general issues that are rarely addressed. Too 
many simplistic associations are allowed to pass without sufficient examination (players of Tekken 3 (1998) or Street Fighter (2000) are more violent in the real world than those who play Ecco the Dolphin (2000), perhaps), and the fictional status of the game and the necessity of the player's recognition of that fictionality, is obscured. And there also seems to be some inconsistency in the responses generated by this form of fiction compared to the responses that greet other forms. The 'realistic' violence of the opening Normandy landing sequence of the film Saving Private Ryan (1998) was critically praised: the 'realism' of first-person shooting games is often subject to condemnation and potential censorship.

It should always be remembered that however much the computer game might be (and particularly have the potential to be) 'more than a game', it is still a fictional form. As a form of mass entertainment, like punk, rock and roll, and the novel before it, the computer game has been seen as offering some sort of threat to society, particularly by providing a space in which otherwise taboo or outlawed behaviour (spitting and swearing, the sexual expression of pelvic gyration, adultery, and aggression as the first resort in problem solving) is given free range. But the confusion of game for real is indicative of individual dysfunction and 'misreading' just as much as the confusion of the films A Clockwork Orange (1971) or Natural-Born Killers (1994) with a template for real behaviour is a misreading. This is fiction, and should be treated, and subject to rigorous examination, just as other forms of fiction are. Its fictionality does not remove the need for the development of an understanding of how it works.

In undertaking a primarily formal analysis of computer games within this book I have restricted myself to the discussion of a fairly narrow range of games that constitute variants of what I term game-fictions. The most interesting contemporary gamefictions, at least for the purposes of this study, are those that borrow heavily from literary and cinematic conventions in the construction of something that resembles a game/fiction hybrid 
(Tomb Raider, Half-Life), games that offer a fictional intersection with historical event in the creation of a species of historical fiction (Close Combat), and games that allow for the creation and management of fictional social constructions (SimCity). Without being overly reductive, and while I fully recognise the fluidity of genre distinctions in such a young and rapidly developing field, my interest is in those genres of games that appear to have the potential to develop into something approximating the sophistication of the currently culturally dominant forms of popular fiction: novels, films, and television programmes. I might be treating those 'shoot'em-ups' that develop story seriously, but I will be avoiding talking at any length about those 'beat-'em-ups' that seem to go nowhere else other than towards 'let's-beat-'em-up-some-more'.

Somewhere in the storytelling of the game-fictions I focus upon, I see fictional possibility and fictional promise. ${ }^{15}$ As the advance of communication and print technology was intimately related to the rise of the novel, and technological advance was inseparable from the development of cinema and television, so one cannot ignore the potential for advances in this new fictional form that may yet accompany this truly startling rise in computer processing power. Given that rise, to assume that the computer game will always be the junior partner in the relationship between itself and other fictional forms might well be naive. ${ }^{16}$ The example offered by those would-be futurologists of the middle of the last century who predicted atomic powered cars, colonies on Mars, and a diet consisting entirely of brightly coloured pills by the year 2000 is salutary, and I do not want to offer too many such hostages to fortune in this volume. But it is already possible to foresee a not too distant future in which the progress of processor technology, if combined with the creative flair we are used to seeing applied in our other forms of popular entertainment, could lead to the development of a generation of games that transcend the pejorative classification of children's entertainment and are taken as seriously as mass-appeal novels and films occasionally are. It would not take 
too much of a leap of the imagination to see the computer game develop into something like a new form of soap opera or action movie. One day, perhaps, the computer game will even produce its À la Recherche du Temps Perdu or its Ulysses, its Casablanca or its Citizen Kane. It is, as yet, early days, and this is a reading of those early days.

\section{Notes}

1 Ernest Hemingway, A Farewell To Arms (London: Grafton, 1977 [1929]), p. 133.

2 Jon Covey (ed.), Fractal Dreams: New Media in Social Context (London: Lawrence and Wishart, 1996), p. xii. See also Kevin Robins 'Cyberspace and the World We Live In' in the same volume, pp. 1-30.

3 A useful introduction to narratological theory can be found in Steven Cohan and Linda M. Shires, Telling Stories: A Theoretical Analysis of Narrative Fiction (London: Routledge, 1988). For an account that then takes narratological analysis to film, and which is therefore of much relevance in the examination of such a visually dependent medium as the computer game, see Jakob Lothe, Narrative in Fiction and Film: An Introduction (New York and Oxford: Oxford University Press, 2000).

4 Jean Baudrillard, 'Aesthetic Illusion and Virtual Reality' in Reading Images, ed. Julia Thomas (Basingstoke: Palgrave, 2001), pp. 198-206.

5 Walter Benjamin, 'The Work of Art in the Age of Mechanical Reproduction' trans. Harry Zohn, in Illuminations: Essays and Reflections (London: Cape, 1970), pp. 211-44. I will return to a consideration of Benjamin's essay in Chapter 6.

6 Baudrillard, 'The Ecstasy of Communication' in Hal Foster (ed.), Postmodern Culture (London: Pluto, 1985), pp. 126-34, p. 127.

7 Fredric Jameson, 'Postmodernism and Consumer Society' in Foster (ed.), Postmodern Culture, pp. 111-25. As Jameson notes in an all too often ignored, and still relevant, opening statement, 'The concept of postmodernism is not widely accepted or even understood today' ( $p$. 111). That the postmodern is the site of debate rather than certainty and has been misrepresented as a straightforward category statement in popular usage has also been reiterated recently in Simon Malpas's introduction to his Postmodern Debates (Basingstoke: Palgrave, 2001), 
a valuable book that includes many of the key essays that have contributed to our understanding of what the multiple meanings of the postmodern might be.

8 Ihab Hassan, 'Towards a Concept of Postmodernism' in Thomas Docherty (ed.), Postmodernism: A Reader (New York and London: Harvester, 1995), pp. 146-56, p. 152. See also Hassan's The Dismemberment of Orpheus: Towards a Postmodern Literature (New York and Oxford: Oxford University Press, 1982).

9 And yet I would not want to make any easy moves to accommodate theoretical models that have a superficial correspondence because they have discussed other 'games' in other contexts. For those conversant with psychoanalytic theory, for example, Sigmund Freud's discussion of the 'fort/da' game provides a case in point. See James Strachey (ed.), Beyond the Pleasure Principle (New York: Norton, 1961). I can imagine an attractive and potentially elegant argument that really does little more than ignore Freud's grounding of his conclusions about the child's game of the disposal and recovery of a toy in observation, and simply substitutes the loss/recovery of the cherished object with the loss ('death')/recovery (reload) of the protagonist of the gamefiction. One can then simply move from the discussion of what is specific to gameplay within game-fictions to making more general assertions about the form. This is not the case in this study.

10 The terms are Roland Barthes from $S / Z$, trans. Richard Miller (New York: Hill and Wang, 1975). Barthes is, like Benjamin, another 'absent presence' beneath much of the argument in this work: as a champion of semiology; as an exceptionally astute reader of popular culture texts (see Mythologies trans. Annette Lavers (London: Paladin, 1972); and as author of The Pleasure of the Text, trans. Richard Miller (Oxford: Blackwell, 1990). I do not have space to tease out the significance of his arguments in the last of these works in full here, but would recommend that any reader interested in pursuing the prioritisation of the pleasure of reading in game-fiction consult this volume.

11 Gérard Genette, Narrative Discourse: An Essay in Method, trans. Jane E. Lewin (Ithaca, NY: Cornell University Press, 1980). See also Palimpsests: Literature in the Second Degree, trans. Channa Newman and Claude Doubinsky (Lincoln, NE: University of Nebraska Press, 1997). 
A coherent and informed account of Genette's thinking in this area can be found in Graham Allen, Intertextuality (London: Routledge, 2000) pp. 95-132.

12 Baudrillard, 'The Precession of Simulacra', in Brian Wallis (ed.) Art After Modernism: Rethinking Representation (New York: New York Museum of Contemporary Art, 1984), pp. 253-82, p. 254.

13 The phrase 'consensual hallucination' is William Gibson's from Neuromancer (London: Gollancz, 1984), p. 12. The extent to which such consensus relies on consent, and therefore on a willed knowing that one agrees to the terms of that consent relates most closely to the discussion of 'immersion' in Chapter 3 of this work.

14 For a collection of essays that looks at Eco's understanding of the 'hyperreal' (that differs from Baudrillard's) in the context of popular culture, see Umberto Eco, Travels in Hyperreality trans. William Weaver and Christine Leefeldt (London: Picador, 1987).

15 Another obvious absence from consideration I will admit to, however, is the multiplayer game. This is not simply a response to the technological limitations imposed by slow Internet connections at the time of writing, that have meant that the number of players within the UK remains relatively insignificant. There are interesting things going on as more and more computer games come bundled with a multi-player option, and new generations of consoles move to provide Internet connections, but this book, with its emphasis on how the reading experience offered by game-fiction texts can be related to the reading experience offered by other forms of narrative fiction, is not the place for their interrogation.

16 For those who like statistics, Steven Poole makes his case with the support of some startlingly large numbers in the opening sections of Trigger Happy: The Inner Life of Videogames (London: Fourth Estate, 2000). Just to add one more number to Poole's, there is something extraordinary in the claim made by Tomb Raider's producers as they moved towards release of another episode in 2002 of twenty-eight million units sold by that date. One only has to multiply that number by the average retail price of the computer game to realise just how significant the computer game has become in terms of an economic (if not necessarily cultural) phenomenon. 